\title{
PENERAPAN MODEL PEMBELAJARAN TUTOR SEBAYA UNTUK MENINGKATKAN HASIL BELAJAR MATEMATIKA SISWA SMP PADA MATERI STATISTIKA
}

\author{
Rismawati $^{1}$, Murhami ${ }^{1}$ \\ ${ }^{1}$ STKIP Muhammadiyah Aceh Barat Daya, Jalan Nasional, Aceh Barat Daya, 23763, Indonesia \\ Email: watirisma2013@gmail.com
}

\begin{abstract}
Abstrak
Penelitian ini bertujuan untuk mengetahui apakah peningkatan hasil belajar siswa dengan menerapkan model pembelajaran tutor sebaya lebih tinggi dari pada pembelajaran konvensional pada materi statistika pada siswa kelas VIII di salah satu SMP Negeri di Susoh, Aceh, Indonesia. Jenis penelitian ini adalah true eksperimen design dengan Pretest-Posttest Control Group Design. Proses pembelajaran pada kelompok eksperimen dengan menerapkan model pembelajaran tutor sebaya dan kelompok kontrol dengan menerapkan pembelajaran konvensional. Populasi dalam penelitian ini adalah seluruh siswa kelas VIII di salah satu SMP Negeri di Susoh yang berjumlah 62 orang siswa, sedangkan jumlah sampel dalam penelitian ini adalah 41 orang yaitu kelas eksperiment 20 siswa dan kelas control 21 siswa. Penelitian ini adalah penelitian eksperiment dengan design pretest-posttest. Teknik pengumpulan data menggunakan tes yang dilakukan pada kelas eksperimen dan kelas kontrol, sedang teknik analisis data digunakan adalah menggunakan uji non parametris Mann-Whitney U-Test. Dari hasil uji hipotesis diperoleh nilai $\mathrm{Z}_{\text {hitung }}<\mathrm{Z}_{\text {tabel }},(-4,88<1,645)$, maka $\mathrm{H}_{0}$ ditolak dan $\mathrm{H}_{\mathrm{a}}$ diterima. Sehingga dapat diambil kesimpulan bahwa "Peningkatan hasil belajar siswa melalui penerapan model pembelajaran tutor sebaya lebih tinggi dari pada pembelajaran konvesional pada materi statistika kelas VIII di salah satu SMP Negeri di Susoh”.
\end{abstract}

Kata Kunci :Hasil Belajar, Statistika, Model Pembelajaran Tutor Sebaya

\begin{abstract}
This research is intended to see the students learning improvement by implementing peer tutorial at the VIII grade student at one of Junior High School in Susoh, Aceh, Indonesia. This research was a true experimental design with Pretest-Posttest Control Group Design. The learning process in the experimental group was by applying the peer tutoring learning model and the control group was by applying conventional learning. The population in this study was all students of class VIII with the total number 62 students, while the number of samples in this study was 41 students, 20 students in experimental class and 21 student in control class. Tests were used to collect the data, to analyze the data, the researchers used the non-parametric Mann-Whitney U-Test. The finding of the hypothesis showed that $\mathrm{Z}$ count $<\mathrm{Z}$ table $(-4,88<1,645), \mathrm{H}_{0}$ was rejected and $\mathrm{H}_{\mathrm{a}}$ was accepted. Therefore it can be concluded that the implementation of peer tutoring learning models is higher than conventional learning at class VIII Junior High Schools, Susoh.
\end{abstract}

Keywords : Learning Outcomes, Statistics, Peer Tutor Learning Model

\section{PENDAHULUAN}

Matematika merupakan ilmu universal yang mendasari perkembangan teknologi modern, mempunyai peran penting dalam berbagai disiplin dan pengembangan daya pikir manusia. Sehingga jika kita melihat realita yang ada dalam kehidupan sehari-hari tidak seorangpun yang bisa lepas dari kegiatan matematika, meskipun mereka tidak menyadarinya. 
Menurut Cornelius (dalam Abdurrahman, 2009:253) mengemukakan tentang lima alasan perlunya belajar matematika karena matematika merupakan : 1). Sarana berpikir logis. 2). Sarana untuk menyelesaikan masalah dikehidupan sehari-hari. 3). Sarana mengenal pola-pola hubungan dan generalsisasi pengalaman. 4). Sarana untuk mengembangkan kreatifitas. 5). Sarana untuk meningkatkan kesadaran terhadap perkembangan budaya. Sedangkan menurut Hudoyo (2005) Matematika adalah suatu alat untuk mengembangkan cara berpikir. Dari pengertian tersebut dapat disimpukan belajar matematika sangat diperlukan baik untuk kehidupan sehari-hari maupun dalam menghadapi kemajuan IPTEK. Namun apabila melihat pengajaran matematika baik disekolah dasar maupun sekolah menengah, masih jauh dari mencapaian tujuan.Tujuannya adalah untuk mempersiapkan siswa agar sanggup untuk menghadapi perubahan keadaan dan terampil serta cakap menyikapinya. Dalam hal ini pembelajaran matematika yang diterapkan di sekolah merupakan dasar yang sangat penting dalam keikutsertaannya mencerdaskan kehidupan bangsa. Pada kenyataanya, yang terjadi saat ini menunjukkan bahwa mata pelajaran matematika tidak begitu dminati oleh sebagian besar siswa, hanya kalangan siswa-siswi tertentu saja yang menyukai pelajaran matematika.

Dari observasi penulis ke SMP Negeri 3 Susoh, diperoleh informasi bahwa hasil belajar siswa masih rendah, yaitu masih banyak siswa yang mendapat nilai kurang dari KKM (70) pada saat UTS dan ulangan.Hal ini disebabkan siswa masih sulit untuk memahami materi yang disampaikan oleh guru, sehingga menyebabkan hasil belajar siswa masih belum memuaskan. Selain itu, siswa juga masih kurang aktif dalam proses belajar mengajar, siswa hanya mendengarkan apa yang disampaikan oleh guru didepan kelas. Dan juga interaksi antara siswa yang satu dengan yang lain masih kurang.

Pembelajaran yang efektif sangat bergantung pada pemilihan dan penggunaan model pembelajaran.Menurut Popham dan Baker (dalam Isjoni, 2011:5) Cara belajar-mengajar yang lebih baik adalah mempergunakan kegiatan murid-murid sendiri secara efektif dalam kelas, merencanakan dan melaksanakan kegiatan-kegiatan sedemikian rupa secara kontinu dan juga melalui kelompok.Meningkatkan hasil belajar matematika banyak usaha yang perlu ditempuh. Salah satu usaha yang dapat dilakukan adalah menerapkan model pembelajaran yang dapat meningkatkan proses belajar mengajar supaya hasil belajar matematika siswa dapat ditingkatkan. Salah satunya dengan menerapkan pembelajaran kooperatif.menurut Hosnan (2013) model pembelajaran kooperatif merupakan suatu model pembelajaran yang mengutamakan adanya kelompok-kelompok yang bekerja sama dalam menyelesaikan permasalahan untuk menerapkan pengetahuan dan ketrampilan dalam rangka mencapai tujuan pembelajaran. Cooperative learning adalah solusi ideal terhadap masalah menyediakan kesempatan berinteraksi secara kooperatif dan tidak dangkal kepada para siswa dari latar belakang etnik yang berbeda (Slavin, 2010:103)

Oleh sebab itu, penggunaan model pembelajaran merupakan salah satu faktor yang penting dalam meningkatkan suatu hasil belajar matematika, sehingga diperlukan adanya suatu model yang baru dalam pembelajaran matematika. Salah satunya yaitu pembelajaran matematika dengan menggunakan pembelajaran kooperatif. Dan banyak sekali model-model dalam pembelajaran kooperatif yang ada maka peneliti menggunakan model pembelajaran kooperatif tutor sebaya.

Ichak dan Warji (dalam Suherman, 2003:276) tutor sebaya adalah sekelompok siswa yang telah tuntas terhadap bahan pelajaran, memberikan bantuan kepada siswa yang mengalami kesulitan dalam memahami bahan pelajaran yang dipelajari. Suryo dan Amin (1984:51) yang dimaksud dengan tutor sebaya adalah seorang atau beberapa orang siswa yang ditunjuk dan ditugaskan untuk membantu siswa-siswa tertentu yang mengalami kesulitan belajar. Pengajaran tutoring merupakan pengajaran melalui kelompok yang terdiri atas satu siswa dan satu pengajar (tutor, mentor) atau boleh jadi seorang siswa mampu memegang tugas sebagai mentor, bahkan sampai taraf tertentu dapat menjadi tutor (Winkel, 1996:401).

Tutor sebaya adalah perekrutan salah satu siswa guna memberikan satu per satu pengajaran kepada siswa lain dalam menyelesaikan tugas yang diberikan melalui partisipasi peran tutor dan tutee. 
Tutor memiliki kemampuan lebih dibandingkan tutee, tapi pada beberapa variasi tutorial jarak pengetahuan yang dimiliki antara tutor dan tutee minimal (Roscoe \& Chi, 2007). Hisyam Zaini (dalam Amin Suyitno, 2002:60) mengatakan bahwa metode belajar yang paling baik adalah dengan mengajarkan kepada orang lain. Oleh karena itu, pemilihan model pembelajaran tutor sebaya akan sangat membantu siswa dalam mengajarkan materi kepada teman-temannya.

Tutor sebaya adalah seseorang atau beberapa orang siswa yang ditunjuk oleh guru sebagai pembantu guru dalam melakukan bimbingan terhadap kawan sekelas. Dengan pembelajaran menggunakan tutor sebaya akan membantu siswa yang nilainya dibawah KKM atau kurang cepat menerima pelajaran dari guru diantara mata pelajaran. Tutor dapat diterima (disetujui) oleh siswa yang mendapat program perbaikan sehingga siswa tidak mempunyai rasa takut atau enggan bertanya kepadanya. Tutor dapat menerangkan bahan perbaikan yang dibutuhkan oleh siswa yang menerima program perbaikan. Tutor tidak tinggi hati, kejam atau keras hati terhadap kawan. Tutor mempunyai daya kreatifitas yang cukup untuk memberikan bimbingan, yaitu dapat menerangkan pelajaran kepada kawan. Model tutorial merupakan cara penyampaian bahan pelajaran yang telah dikembangkan dalam bentuk modul untuk dipelajari siswa secara mandiri. (Martinis, 2007)

Dari uraian diatas dapat disimpulkan bahwa, model pembelajaran tutor sebaya adalah pembelajaran yang pelaksanaannya dengan membagi kelas dalam kelompok-kelompok kecil, dimana seorang atau beberapa orang siswa yang pandai ditunjuk dan ditugaskan untuk membantu siswa yang kurang pandai.

Keberadaan model pembelajaran serta pendekatan pembelajaran sangatlah mendukung peningkatan mutu pendidikan disamping fasilitas, buku-buku penunjang, kompetensi guru, kurikulum serta administrasi pendidikan. Namun demikian, untuk mencapai pendidikan yang benar-benar berkualitas bukanlah perkara mudah.Masih dijumpai permasalahan-permasalahan yang ada didunia pendidikan, seperti hasil belajar yang rendah, siswa yang pasif dalam pembelajaran, siswa kurang bisa mengembangkan potensinya.Tidak hanya itu sosialisasi dengan teman sekelaspun perlu dibina, agar tercipta suasana belajar yang bermanfaat serta tidak merasa lagi bahwa dalam matematika hanya menghitung saja. Matematika bukan hanya menghitung tetapi juga berlatih tentang masalah-masalah praktis kehidupan serta belajar berpikir kritis dan kreatif. Untuk itu diperlukan suatu model pembelajaran dan pendekatan yang mendukung hal tersebut.

Beberapa peneliti terdahulu telah meneliti tentang penerapan pembelajaran tutor sebaya diantaranya penelitian Aina (2017:92) diperoleh bahwa penerapan pembelajaran tutor sebaya dapat meningkatkan hasil belajar siswa pada materi komposisi fungsi siswa kelas XI di MAS Babun Najah Banda Aceh. Begitu juga dengan penelitian yang dilakukan oleh Wardiyyah (2009:67) diperoleh kesimpulan bahwa hasil belajar matematika siswa dapat ditingkatkan melalui model pembelajaran tutor sebaya pada kelas VII MTs NU Banat Kudus pada materi operasi bilangan bulat. Selain itu penelitian yang dilakukan oleh Tamimy (2015:91) diperoleh bahwa penerapan model tutor sebaya dapat meningkatkan hasil belajar matematika siswa kelas VIII di SMP Negeri 2 Pogalan Trenggalek pada pokok bahasan sistem persaamaan linear dua variable. Namun mereka hanya meneliti pada materi komposisi fungsi, operasi bilangan bulat dan system persamaan linear dua variabel sedangkan penelitian penerapan pembelajaran tutor sebaya pada materi statistika belum dilakukan, disamping itu dari hasil observasi juga diperoleh informasi belum pernah diterapkannya model pembelajaran tutor sebaya di SMP susoh, dan pemahaman siswa juga rendah pada materi statistika hal ini terlihat dari hasil ulangan siswa pada materi tersebut. Oleh karena itu penulis tertarik ingin mengetahui apakah peningkatan hasil belajar siswa dengan menerapkan model pembelajaran tutor sebaya lebih tinggi dari pada pembelajaran konvensional pada materi statistika. 


\section{METODE PENELITIAN}

Jenis penelitian ini adalah penelitian eksperimen dengan pendekatan penelitian kuantitatif.Penelitian ini berbentuk penelitian eksperimen jenis true experiment dengan desain pretest and posttest group. Tes yang dilakukan sebanyak 2 kali yaitu sebelum eksperimen (pretest) dan sesudah eksperimen (posttest).True-eksperimental menggunakan tes untuk mengevaluasi hasil belajar siswa. Pada kelas eksperimen diterapkan model pembelajaran tutor sebaya, sedangkan pada kelas kontrol pembelajaran menggunakan konvensional.populasi dalam penelitian ini adalah seluruh siswa kelas VIII di salah satu SMP Negeri Susoh Tahun Ajaran 2018/2019 yang berjumlah 62 orang siswa sedangkan sampel dalam penelitian ini adalah siswa kelas VIII $^{1}$ yang berjumlah 20 orang siswa sebagai kelas eksperimen dan siswa kelas VIII ${ }^{2}$ yang berjumlah 21 orang sebagai kelas kontrol.

Analisis data dalam penelitian ini menggunakan uji statistik non parametris Mann-whitney yang dikemukakan Sugiyono (2011:155):

$$
Z=\frac{U-\frac{n_{1} \cdot n_{2}}{2}}{\sqrt{\frac{\left(n_{1}\right)\left(n_{2}\right)\left(n_{1}+n_{2}+1\right)}{12}}}
$$

Dengan kriteria pengujian tolak $\mathrm{H}_{0}$ jika $Z_{\square \text { itung }} \leq Z_{\text {tabel }}$ dan terima $\mathrm{H}_{0}$ jika sebaliknya pada taraf signifikan $\alpha=0,05$.

\section{HASIL PENELITIAN DAN PEMBAHASAN}

Berdasarkan hasil pengolahan data yang sudah dilaksanakan diperoleh bahwa kedua kelas tersebut memiliki data yang homogen, sedangkan pengujian normalitas diperoleh bahwa data tidak berdistribusi normal maka pengujian hipotesis dilanjutkan dengan uji non parametris Mann Whitney berdasarkan perhitungan diperoleh $Z_{\text {hitung }}$ sebesar $-4,88$ dengan demikian maka diperoleh nilai $Z_{\text {hitung }}<Z_{\text {tabel }},(-4,88<1,645)$, maka $H_{O}$ ditolak dan $H_{a}$ diterima. Artinya peningkatan hasil belajar siswa dengan penerapan model pembelajaran tutor sebaya lebih tinggi dari pada pembelajaran konvensional pada materi statistika siswa kelas VIII di salah satu SMP Negeri Susoh Aceh Barat Daya.

Dari hasil penelitian tersebut diperoleh bahwa model tutor sebaya sangat cocok diterapkan pada mata pelajaran matematika khususnya pada materi statistika karena dengan menerapkan model ini pembelajaran tidak akan membosankan, dan siswa akan memiliki peran aktif untuk menentukan kegiatan pembelajaran yang akan dilaksanakan, sehingga pembelajaran akan lebih bermakna. Hal ini terjadi karena model tutor sebaya, siswa dituntut untuk lebih aktif dalam memahami materi dengan mencari sendiri informasi yang dibutuhkan. Siswapun dituntut untuk bisa berkolaborasi dan bekerja sama dalam sebuah kelompok.

Hasil penelitian ini didukung oleh teori yang melandasi model tutor sebaya, yaitu teori Piaget, dimana ilmu pengetahuan yang dibangun dalam pikiran anak akibat dari interaksi secara aktif dengan lingkungannya melalui proses asimilasi dan proses akomodasi. Selanjutnya diperkuat oleh teori Vygosky relevan dengan model tutor sebaya dimana belajar bagi anak dilakukan dalam interaksi dengan lingkungannya sosial maupun fisik.

Berdasarkan teori-teori tersebut maka penelitian yang dilaksanakan ini tidak jauh berbeda dengan penelitian yang dilaksanakan oleh aina (2017) dan Wardiyyah (2009) dimana model tutor sebaya dapat meningkatkan hasil belajar siswa menjadi lebih tinggi dari pada hasil sebelum pelaksanaan pembelajaran tutor sebaya. 


\section{KESIMPULAN}

Berdasarkan hasil penelitian dan analisis data yang sudah dilaksanakan maka dapat ditarik kesimpulan bahwa peningkatan hasil belajar siswa dengan penerapan model pembelajaran tutor sebaya lebih tinggi dari pada pembelajaran konvensional pada materi statistika siswa kelas VIIIdi salah satu SMP Negeri Susoh Aceh Barat Daya.

Guru mata pelajaran matematika disarankan dapat menggunakan model pembelajaran tutor sebaya sebagai salah satu alternatif pemilihan model pembelajaran karena berdasarkan hasil penelitian ini terbukti mampu meningkatkan hasil belajar siswa pada materi statistika.

\section{REFERENCES}

Abdurrahman, M. (2009). Pendidikan Bagi Anak Berkesulitan Belajar. Jakarta : Rineka Cipta.

Aina, H. (2017). Penerapan Pembelajaran Peer Tutor Untuk Meningkatkan Hasil Belajar Siswa pada Mata Pelajaran Matematika di Mas Babun Najah Banda Aceh .Banda Aceh : UIN Ar-Raniry.

Arikunto, S. (2006). Prosedur Penelitian Suatu Pendekatan Praktik. Jakarta : Rineka Cipta.

Baharuddin dan Esa. (2007). Teori belajar dan pembelajaran. Yogyakarta: AR-Ruzz Media.

Dahar. (2011). Teori-Teori Belajar Dan Pembelajaran. Jakarta : Erlangga.

Dimyati Dan Mudjiono. (2006). Belajar Dan Pembelajaran. Jakarta : Rineka Cipta

Djamarah. (2003). Strategi Belajar Mengajar. Jakarta : Rineka Cipta.

Fathani, A. (2012).Matematika Hakikat Dan Logika. Jakarta : Ar-Ruzz Media.

Hamalik, O. (2011).Proses Belajar Mengajar. Jakarta: PT Bumi Aksara.

Hasratuddin. (2015). Mengapa Harus Belajar Matematika. Medan : Perdana Publissing

Hosnan.(2014). Pendekatan Saintifik dan Konstektual dalam Pembelajaran Abad 21. Jakarta: Ghalia Indonesia

Hudoyo, H. (2005). Pengembangan Kurikulum dan Pembelajaran Matematika.Malang : UM Press

Irianto, A. (2011).Pendidikan Sebagai Investasi dalam Pembangunan Suatu Bangsa.Jakarta : Kencana

Isjoni. (2011). Pembelajaran Kooperatif : Meningkatkan Kecerdasan Komunikasi Anatar Peserta Didik. Yogyakarta : Pustaka Belajar.

Rusman. (2011). Model-Model Pembelajaran. Jakarta : Rajawali Press.

Russefendi. (2004). Dasar-Dasar Matematika Modern. Bandung. Tarsito. 
Roscoe, R.D., \& Chi, M.T.H. (2007). Understanding Tutor Learning: Knowledge Building and Knowledgetelling in Peer Tutors' Explaination and Questions. Review of Education Research, 77 (4):534-574

Saminanto, (2012) Ayo Praktek PTK, Semarang: Rasail Media Group.

Slameto.(2010). Belajar Dan Faktor-Faktor Yang Mempengaruhinya.Jakarta : Rineka Cipta.

Sugiyono. (2015). Statistik Non Parametris untuk Penelitian. Bandung: Alfabeta

Suhartono, S. (2009). Filsafat Pendidikan. Yogyakarta : Ar-Ruzz Media.

Suherman, (2003). Strategi Pembelajaran Matematika Kontemporer, Bandung: JICA.

Suprijono. (2010). Cooperative Learning Teori dan Aplikasi Paikem. Yogyakarta : Pustaka Belajar.

Susanto, A. (2013).Teori Belajar dan Pembelajaran.Jakarta : Kencana Prenamedia Group.

Sutikno, S. (2009). Belajar dan Pembelajaran.Bandung : Prospect.

Suyitno, Amin. (2004). Dasar-Dasar Proses Pembelajaran Matematika. Bahan Ajar, S1Program Studi Pendidikan Matematika. Semarang:UNNES

Tamimy, F. (2015). Penerapan Model Pembelajaran Tutor Sebaya untuk Meningkatkan Hasil Belajar Matematika Siswa pada Materi Spldv Kelas VIII SMP Negeri 2 Pogalan Trenggalek.Tulungagung : IAIN Tulungagung

Thobroni Dan Mustofa. (2013). Belajar dan Pembelajaran. Jakarta : Ar-Ruzz Media.

Wardiyyah, N. (2009). Penerapan Model Pembelajaran Tutor Sebaya untuk Meningkatkan Hasil Belajar Peserta Didik Kelas VII MTs NU Banat Kudus pada Materi Pokok Operasi Bilangan Pecahan Semester 1 Tahun Ajaran 2009/2010.Semarang : IAIN Walisongo Semarang. 